\title{
Further evidence of novel sex differences in chiasma distribution in marsupials
}

\author{
D. L. Hayman, \\ H. D. M. Moore $†$ and \\ E. P. Evans $\ddagger$
}

\author{
* Genetics Department, University of Adelaide, \\ South Australia 5000. \\ † Institute of Zoology, London Zoo, \\ Regent's Park, London, U.K. \\ ¥Sir William Dunn School of Pathology, \\ South Parks Road, Oxford, U.K.
}

At meiosis in the male of the South American species Monodelphis domestica (Marsupialia: Didelphidae) there are some 21 chiasmata per cell and two-thirds of these are interstitial. Interstitial chiasmata are very rare in the female and there are fewer chiasmata per cell. These observations parallel those found in the only other marsupial (an Australian species) for which data are available. This similarity suggests that these differences between the sexes are of great antiquity, are present in two of the largest families of marsupials and may well be characteristic of other marsupials.

\section{INTRODUCTION}

In a combined genetical and cytological study of the fat-tailed dunnart Sminthopsis crassicaudata (Marsupialia: Dasyuridae), Bennett et al. (1986) reported a novel sex difference manifested both by linkage values and chromosome behaviour at meiosis. Genetic data involving joint segregation of genes in each of two independent autosomal linkage groups showed that recombination values were high in the male and very low in the female. Correspondingly, at meiosis in the male, more than half the observed chiasmata were interstitial, while in the female the chiasmata were terminal or subterminal and fewer in number per cell. These striking differences are the reverse of the observations which have been made in eutherian mammals. Here differences in recombination between the sexes are less extreme and, where they occur, it is usual for the female to have the higher values.

Genetic data were not available from other marsupial species nor were there any other comparisons of chiasmata between the male and female of the one marsupial species. Thus it has not been possible to determine whether this novel difference reported in Sminthopsis is present in other marsupials.

The only other small laboratory bred marsupial is Monodelphis domestica $(2 n=18 \mathrm{XX} / \mathrm{XY})$. An account of this South American species has been given by Fadem et al. (1982) and some of its cytological features have been described by Merry et al. (1983). Baggott et al. (1987) described a behavioural programme to bring females of this species into pro-oestrus in a predictable manner. This technique results in a potential supply of females with oocytes undergoing meiosis. Here we report on a comparative study of chiasmata at meiosis in the two sexes of $M$. domestica. In addition, a comparison of the G-banding pattern of the mitotic chromosomes of this species, of Caluromys lanatus (another South American species with $2 n=14 \mathrm{XX} / \mathrm{XY}$ and of Acrobates pygmaeus (an Australian species with $2 n=14$ $\mathrm{XX} / \mathrm{XY}$ ) is described.

\section{MATERIALS AND METHODS}

The colony of Monodelphis, from which the experimental animals were derived, was developed from animals obtained from the Southwest Foundation for Biomedical Research, San Antonio, Texas, in 1983. Short term oocyte culture using techniques successful with Mus musculus failed to yield divisions. Meiotic divisions were obtained from oocytes taken from animals shortly after mating. While mating is not an accurate index of the precise state of meiosis in the oocyte, it provided a guide to the division. The oocytes are $200 \mu$ in diameter, contain substantial amounts of fat and 
the chromosomes are confined to a very small area of the oocyte. Oocytes, freed from cumulus cells, were pretreated for two minutes with $0.075 \mathrm{M} \mathrm{KCl}$ before being fixed following the procedure of Tarkowski (1966).

Tubules from the testes were washed once in isotonic solution and pretreated for 15 minutes in $0.075 \mathrm{M} \mathrm{KCl}$ before fixation in methanol acetic acid. Slides were prepared the next day after disaggregation of the tubules in 60 per cent acetic acid. There are a very low number of cells at diplotene and the later stages of meiosis in Monodelphis, compared with other marsupial species.

G-banding was carried out on mitotic divisions derived from cultured fibroblasts.

\section{RESULTS}

At meiosis in the male there are an average of 21.5 chiasmata amongst the autosomal chromosomes, based on 17 cells at diplotene. More than twothirds of the chiasmata are interstitial. The largest bivalent is readily recognisable and characteristically has four or five chiasmata. Typical cells are shown in fig. 1(a) and (b).

The meiotic events in the oocyte, following the release from dictyotene, occur very quickly-only three cells were observed at diplotene. Many cells were obtained at metaphase; the chromosomes at this stage are very compacted, often clumped together, and identification of all nine bivalents was rarely possible.
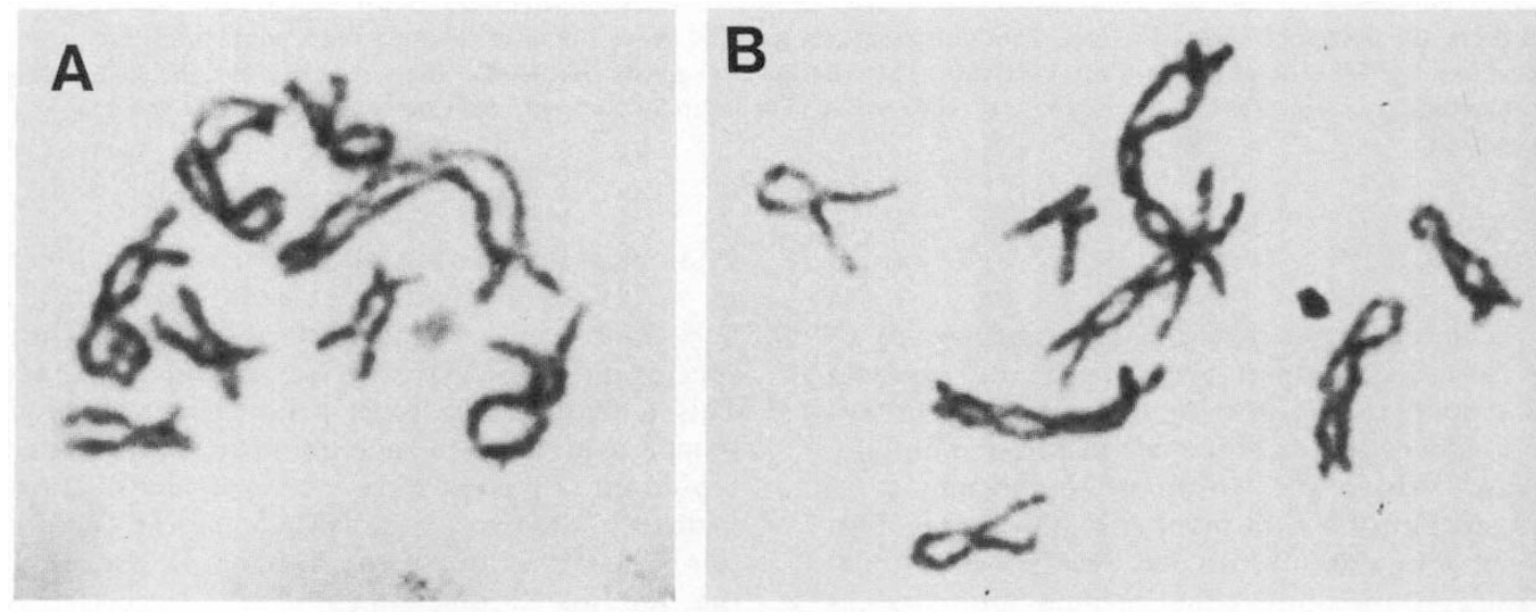
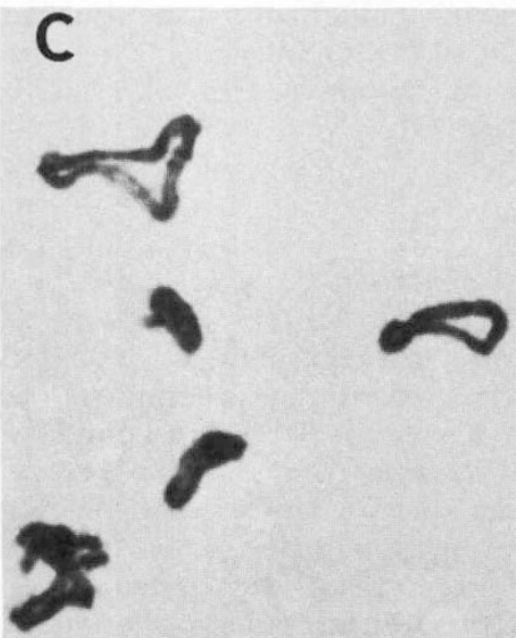

Figure 1 (a) and (b) Diplotene from meiosis in the male of Monodelphis domestica. The large bivalents show many interstitial chiasmata; (c) diakinesis, and (d) metaphase I from meiosis in the female $M$. domestica showing an absence of interstitial chiasmata. 


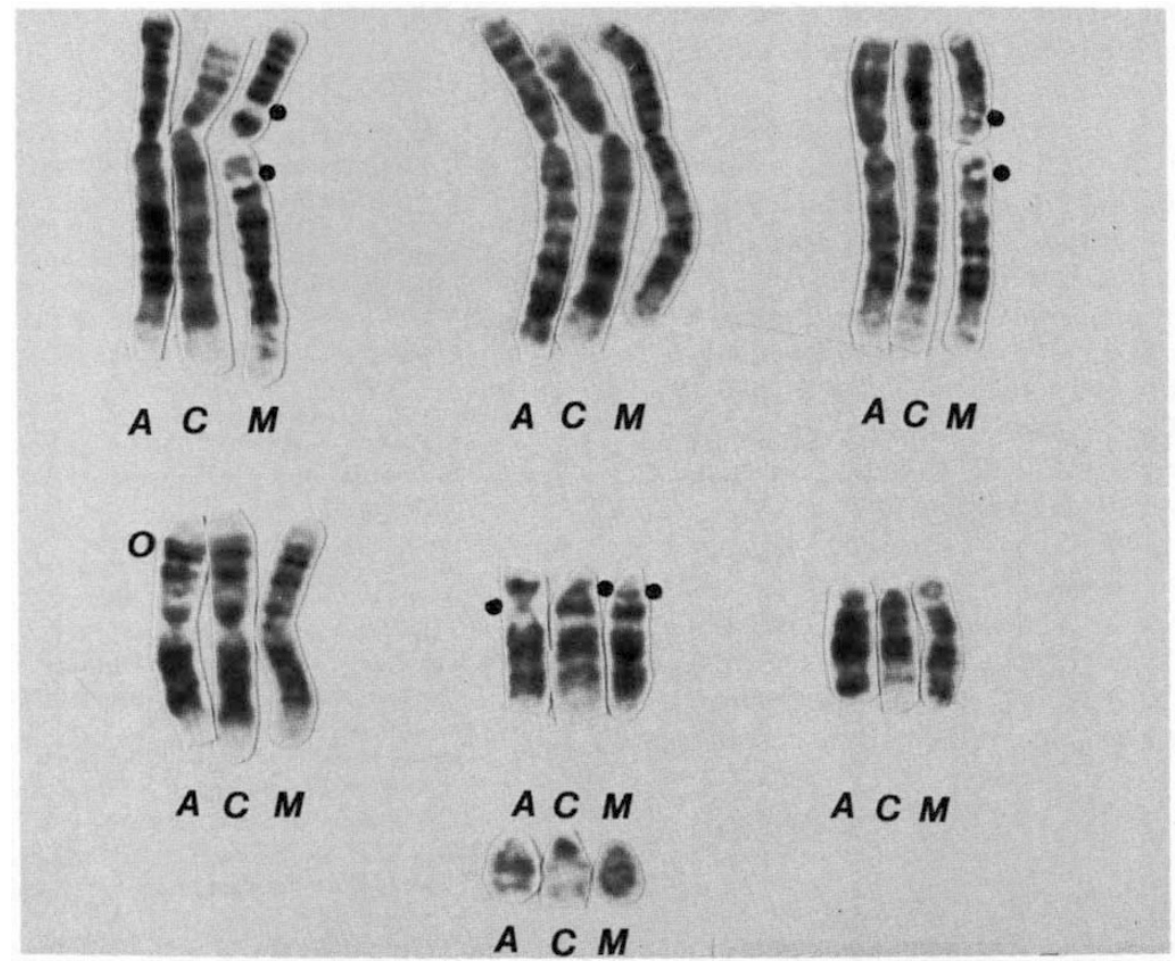

Figure 2 G-banded chromosomes of (A) Acrobates pygmaeus, (C) Caluromys lanatus, and (M) Monodelphis domestica. The positions of the centromeres are indicated by dots. The X-chromosomes are the smallest.

Chiasmata were almost always terminal or subterminal and the large bivalents, in particular, contained no more than two chiasmata (see fig. 1(c) and (d)). The average number of chiasmata per cell was 13 .

The G-banding pattern found in the nine chromosomes of Monodelphis were compared (see fig. 2) with those patterns observed in the Australian species Acrobates pygmaeus $(2 n=14)$ and the American species Caluromys lanatus $(2 n=14)$. The similarity between the banding patterns is evident.

\section{DISCUSSION}

A very close similarity is evident between the two marsupial species $S$. crassicaudata and $M$. domestica in the differences in chiasma distribution between the sexes. It is to be anticipated, therefore, that there would be a corresponding substantial restriction of genetic recombination in the female of $M$. domestica compared to that found in the male. The time of divergence between the South American and Australian marsupial fauna is estimated to be some $45 \times 10^{6}$ years (Falvey and
Mutter, 1981). The demonstration that this novel sex difference is present in the only representatives studied in both faunas suggests that its possession by marsupials predates the time of divergence. Further, this difference is present in two of the largest families of marsupials, and may well be present in other marsupials. By this argument, marsupials have adopted a variant strategy in regulating recombination to that possessed by other mammalian species for which data are available.

While it is known that the level of recombination in any organism is under genetic control and thus subject to the operation of natural selection, no satisfactory explanation exists for the different levels of recombination that are found in different groups. Burt and Bell (1987) have surveyed published data on chiasma frequency from males of 24 mammalian species. They report positive correlations between chiasma frequency and age to maturity and weight, and negative correlations with litter size. An examination of chiasma frequency in the males of 33 species of marsupial reports similar correlations (Sharp and Hayman, 1988). The results of the study reported here show that this similarity occurs when the average amount 
of recombination per generation is reduced by approximately half due to the operation of this sex difference.

Restriction of recombination largely to the male sex has interesting consequences for the Xchromosome, since it would follow that genes on this chromosome would be more likely to be subject to linkage disequilibrium.

Chromosome evolution in marsupials has been shown by G-banding to involve little repatterning other than that of chromosome fusion, fission and inversion. The same G-banding elements and chromosome morphology are shared by Austrailan and American species (Hayman et al., 1987; Rofe and Hayman, 1985). The evidence supports an hypothesis of a basic $2 n=14 \mathrm{XX} / \mathrm{XY}$ complement for the group as a whole. $M$. domestica has a complement basically unchanged from this basic complement found in $2 n=14$ Australian and American species apart from two chromosome fissions.

\footnotetext{
Acknowledgements This study was carried out while D. L. Hayman was an Honorary Visiting Scientist at the Institute of Zoology. Grateful acknowledgement is made to the Wellcome Trust and the Clive and Vera Ramaciotti Foundation for providing financial support. H. D. M. Moore is supported by a grant from the Nuffield Foundation.
}

\section{REFERENCES}

BAGGotT, L. M., BUTLER-DAVIS, S. AND MOORE, H. D. M. 1987. Characterisation of oestrus and timed collection of oocytes in the grey short-tailed opossum, Monodelphis domestica. J. Reprod. Fert., 79, 105-114.

BENNETT, J. H., HAYMAN, D. L. AND HOPE, R. M. 1986. Novel sex difference in linkage values and meiotic chromosome behaviour in a marsupial. Nature, 233, 59-60.

BURT, A. AND BELL, G. 1987. Mammalian chiasma frequencies: A critical test of two theories of recombination. Nature, 326, 803-805.

FADEM, B. H., TRUPIN, G. L., MALINIAK, E., VANDEBERG, J. L. AND HRYSSEN, V. 1982. Care and breeding of the grey short-tailed opossum (Monodelphis domestica). Lab. Anim. Sci., 32, 405-409.

FAlVEY, D. A. AND MUTTER, J. C. 1981. Regional plate tectomics and the evolution of Australia's passive continental margins. Bur. Mineral Resources Austral. Geo. Geograph., 6, 1-30.

HAYMAN, D. L., ROFE, R. AND SHARP, P. 1987. Chromosome evolution in marsupials. Chromosomes Today, 9, 91-102.

MERRY, D. E., PATHAK, S. AND VANDEBERG, J. L. 1983. Differential NOR activities in somatic and germ cells of Monodelphis domestica (Marsupialia, Mammalia). Cytogenet. Cell Genet., 35, 244-251.

ROFE, R. AND HAYMAN, D. L. 1985. G-banding evidence for a conserved complement in the Marsupialia. Cytogenet. Cell Genet., 39, 40-50.

SHARP, P. J. AND HAYMAN, D. L. 1988. An examination of the role of chiasma frequency in the genetic system of marsupials. Heredity (in press).

TARKOWSKI, A. K. 1966. An air drying method for chromosome preparations from mouse eggs. Cytogenetics, 5, 394-500. 